\title{
Public Interpretation of the Political and Legal Process in Modern Russia as a Challenge to Social Consensus
}

\author{
Alexander P. Fedorovskiy ${ }^{1}$, Nikolay V. Petrov ${ }^{2}$, Irina V. Petrova ${ }^{1, *}$ \\ ${ }^{1}$ North Caucasian Social Institute, Stavropol, Russia \\ ${ }^{2}$ North Caucasus Federal University, Stavropol, Russia \\ ${ }^{*}$ Corresponding author.Email: petrova_sksi@mail.ru
}

\begin{abstract}
The article reveals the effectiveness of the representation of the activism of power structures in the field of politics and law, the features of its social recipient at the theoretical and methodological level, and also establishes the relationship between the explicitness of the statist discourse and the political loyalty of society and the state of its legal consciousness. Particular attention is paid to the meaning of the stimulation of lawmaking and management practices, which has become an attribute of the last few decades of Russian history. The methodological basis of the proposed research was the concept of "communicative action" (J. Habermas), supplemented by separate components of the critical theory. The authors of the article seek to point out the social danger of the institutional and managerial "occupation" of the life world, which occurs against the background of the absence of the necessary "codes" for the society to understand both the actual power decisions taken at the societal level and the acceleration of the corresponding dynamics.

Keywords: statist discourse, stimulation of managerial action, interpretation of the political and legal process, life world, JEL Classification Codes K10, I3
\end{abstract}

\section{INTRODUCTION}

The choice of this topic is due to the understanding of the danger of the growing alienation of the authorities and society, caused not only by the specific activities of the authorities, but also by their inability to convey to the broad masses the meaning, expediency and consequences of decisions taken, as well as of laws being issued. Although the lack of communication between the ruling class and the masses has invariably been one of the main factors of the domestic political and legal tradition, being the basic principle of the existence of Russian statehood in its retrospect, by now it is increasingly turning into a challenge that threatens to destroy the existing social consensus. The fact that the launch of the mechanisms of destruction of the latter was initiated by the management corps is noted by many representatives of the expert community, pointing out, at the same time, the growth of "grassroots" social activity developing in the existing communicative vacuum. As V. Petukhov points out, the actualization of the request for change was, to some extent, a response to the attempts of the elites to dissolve the unspoken "paternalistic consensus". Its destruction motivated many Russians to active social action, to collective self-organization for problems that they see as socially significant and which the authorities cannot and do not want to solve" [1].

\section{METHODOLOGY}

There are several reasons for the emergence of a social demand for clarity in the actions of the executive and legislative branches. For example, a dynamically developing civil society, the actual acquisition by Russia of the status of an "open society", the destruction of spatial and temporal barriers, facilitated access to information sources, which makes it possible to compare the content of the official discourse with other information resources and that specific emiric reference to which it claims to be ... According to A. Glukhov, the competencies associated with the use of new media become elementary skills necessary for life in modern society [2].

It should also point to the radically increased level of critical thinking, which led to the erosion of loyalist attitudes, localized in the deep structures of social consciousness and for a long time forming the dominant of the latter. At the same time, there is an increase in the authority of the expert community, which is increasingly influencing the formation of a critical attitude of public opinion.

The loss of intelligibility by managerial and law-making practices, as a rule, is associated with the deformation of their form and content. A striking example of the first is the discursive fixation of the topic of social reform, 
articulating the continuity of the changes initiated by the authorities.

When such discursive constructs are promoted, their automatic rejection occurs, covering both emotional and rational levels. First, the promise to continue reforming society is a serious irritant for the collective consciousness traumatized by the 90 s of the 20th century, and secondly, there is no clear explanation of the expediency, temporal boundaries and the desired effectiveness of permanent changes. Moreover, the skepticism that is present falls on the fertile soil of social empiricism, which often testifies far not in favor of the managing subject, as evidenced by numerous and unsuccessful attempts to reform the pension system.

There is also a socio-psychological aspect of the problem. In a situation where there is no clear understanding of his own prospects, as well as the prospects of society as a whole, a social actor is deprived of the opportunity to carry out even direct daily planning, not to mention building a long-term life strategy, thereby finding himself in a state of severe protracted stress, uncertainty about the future. trying in vain to see some fundamental in the multidirectional market trends.

\section{RESULTS}

Monitoring lawmaking and institutional executive decisions covering the entire post-Soviet period reveals not only the presence of a continuum of radical transformations, but a continuum of internally very contradictory, devoid of logical integrity, which also deforms the possibility of conducting a constructive dialogue between the authorities and society. The complex of contradictions in question covers many areas of the functioning of society, such as economics, politics, culture, and the social sphere.

The sphere of the historical consciousness of Russian society, which in many ways plays a worldview and selfidentification and evaluative role, turns out to be one of such spheres. For example, one set of power aspirations lies in the plane of the traditionalist interpretation of modernity, which positions the latter as a simple projection of a sociocultural retrospective. The meaning of the decisions lobbied by part of the ruling class is to reproduce in the present a modernized retrospective social model. The essence of such an approach to social management is described by I. Tsifanova, who rightly insists that the legitimation of social institutions, structures and functions is inextricably linked with selfidentification, which is based on the combination of historical narrative with social self-description [3].

On the other hand, we are witnessing steps aimed at rejecting the historical "background", attempts to write a political and legal history "from scratch", to declare not continuity, but discreteness of historical development. This approach is associated with political subjectivity and voluntarism of the $90 \mathrm{~s}$ of the 20th century, when the ruling elite had an illusory sense of time of absolute possibilities, devoid of objective historical determinism, free from fundamental moral imperatives. Oscillations in the area of historically set landmarks continue in our time. Professor S. Shevchuk notes the preservation of the "longestablished positions of the legislator" with their simultaneous "significant additions" [4]. The amplitude of fluctuations reaches its maximum values in the field of family law in addition to other areas of law (the so-called liberal "juvenile justice" against conservative "adoption by foreign citizens"), as well as in certain aspects of the legal definition of self-regulation of civil society.

A much more global problem related to the project of Russian statehood as such is hidden behind the contradictory empiric of legislative and administrative practices. It seems that there is no corresponding consensus among the elites. Moreover, one and the same politician can make mutually exclusive statements regarding the agenda for the global future, the role and place of the Russian Federation in this agenda. On the one hand, adherence to integrativist ideology is emphasized in every possible way, and, on the other, political discourse acquires a distinct isolationist tone.

In addition, there are difficulties associated with the reaction to the accelerating dynamics of the processes taking place both inside the country and abroad. In this case, it is about the political and legal reaction, or rather, about their consequences for the population of the country. In our opinion, there has been a dangerous divergence in public assessments of the domestic and foreign policy courses. If the foreign policy is met with almost absolute approval and support in the broadest strata of society, then the attitude towards the domestic policy is more than skeptical. We believe that such a "bifurcation" of the collective consciousness has no chances to persist in any significant future, since the increasing interconnection of problems within the country and actions of the state in the international arena becomes more and more obvious. Problems with the export of domestic energy resources, limited access to external sources of financing and high technologies, sanctions ostracism and other steps unfriendly towards Russia on the part of a number of states will be considered by public opinion from the point of view of the political course as such. Although the opposition to the conventional "West" has long been formed into a constant of the historical memory of our people, the degree of modern mutual confrontation for public reflection has a transcendent character.

The contradictions of modern social policy need a separate discussion. The latter is seen by a large number of experts as being extremely eclectic, since it combines mutually exclusive principles and approaches. As E. Danilova notes: "We see the problem in maneuvering between the neoliberal logic of reforms, which, on the one hand, consists in the introduction of market fundamentals, in the decentralization of management of the social sphere and individualization of risks, and on the other hand, in 
the increasing role of the state, expressed in the distribution of budgetary resources and the growing regulation of the social sphere" [5].

However, the complex of problems existing here is not limited only to the incompatibility of two basic philosophies that are simultaneously present in the implementation of social policy. An equally important reason was the stratification atomization, which affected each specific social group. Communication between representatives of different strata has been reduced to the minimum indicators of modern Russian history. The reaction of society to the announcement by one or another official of the average indicators of the level of the people's well-being serves as a clear evidence. Society reacts with undisguised skepticism to the attempts of representatives of power structures to extrapolate the growth of prosperity into the future. Direct confrontation between the regional authorities and local communities pushed the President of the Russian Federation to a sharp statement about the inadmissibility of civil servants deviating from the established ethical norms during their communication with the population.

Another problem is the established order, in which the task of improving the quality of management occurs through the transformation of the institutional system, and not through the strengthening of requirements for the human factor. Thus, an involuntary choice is made in favor of the institutional approach, which is recognized as an alternative to the behavioral one. The imbalance in the use of the above two approaches seems to us erroneous for at least two reasons.

First of all, the specificity of the traditional Russian mentality is not taken into account, for which the role of the individual is much more important than the institution it represents. In this sense, the Russian society is invariably positioned as a spontaneous behaviorist. We should agree with the position of I. Przhilenskaya, postulating the dependence of social systems on the "nonsystemic life world, existing according to the laws of meaning" [6].

On the other hand, there is a certain exaggeration of the role of institutions as determinants of social progress, "we are talking about the so-called 'good institutions', the discussions about which began in connection with the revision of the macro factors affecting development, and the role of individuals who were supposed to be more independent" [5].

Domestic elites quite often resort to the mechanistic borrowing of foreign experience in state-building, trying to "inculcate" it into Russian realities, guided by the logic of "catch-up modernization". Specific management models, being emancipated from the socio-cultural context in which they were successfully tested, often do not provide the desired result, stimulating further unpromising form-creation in the field of social management.

We see the achievement of proper mutual understanding between the authorities and society in terms of a more attentive attitude of the authorities towards public opinion. The citizens of our country are increasingly demanding the status of a full-fledged participant in the management process, which is confirmed by both the growth of "street" activity and the content of online network communications. Representatives of civil society are increasingly raising the issue of the redistribution of power in their favor.

In reality, we are talking about supplementing the communicative vertical with its most important links represented by the broad masses, whose position, as a rule, turns out to be not just poorly taken into account, but also completely ignored. Mechanisms for the production and implementation of public initiatives and projects should be developed and launched. Until this happens, the archaic model of social management continues to persist, to which E. Danilova, already mentioned by us, indicates its limitations. E. Danilova notes that the practice of making decisions and innovations in the social sphere is such that the initiative comes from above, the initiators of innovations, as a rule, are the authorities (state structures), and the legislative or normative consolidation of the initiative should be preceded by numerous expert discussions. The population, as a rule, is poorly involved in this process. [5]. At the same time, we emphasize the idea that even the existing practice of sociological surveys in this area is clearly insufficient, since it reveals not the request itself coming from the bottom, but only the nature of the reaction to a potential decision of the authorities. However, even the obtained ideas about this reaction turn out to be superficial, and therefore unproductive from the point of view of their information content.

At the same time, there is the problem of interpreting the obtained sociological data. Primary sociological material is necessarily subjective by virtue of its nature, and often it is also deliberately distorted. Aberrations about seeing social sentiment arise in different ways. This may be the desire of the performer of a research project, to "please" the customer in the person of one or another authority that provides project funding. In addition, a distorted representation of sociological data takes place at the level of lower management structures that act as counterparties of the sociological team and do not want to present negative data to their leaders, which can be regarded by the latter as the low efficiency of these structures themselves. Thus, a decrease in public expectations associated with state support can be interpreted as a decrease in the share of paternalistic consciousness and a person's transition to the search for development potential within himself. However, in reality, it would be more correct to speak not about the emergence of a selfsufficient social actor, but about a simple change in the subject of support, whose role is now being played by credit organizations, relatives, acquaintances, etc.

The authorities quite often use the method of replacing discursive constructs with negative connotations with their antinomies. The purpose of such conceptual manipulations is the prolonged localization of society in 
the zone of psychological comfort, where it should be, the thoughts of the ruling class, despite the radically changed situation for it. Thus, the refusal of the state from its social obligations is presented as a rejection of vicious paternalism, and the violation of the principle of social justice is served by the transition to a society of equal opportunities. However, as practice shows, such verbal tricks are characterized by low efficiency and eventually turn into the vocabulary of "hatespeech", which happened with the ultra-liberal discursive practices of the 90s, which are today the strongest social irritant. Researchers have recorded "historical adherence to linguistic constants" and the impossibility of their "redesignation in accordance with other samples" [7].

A. Fedorovsky also speaks of such verbal metamorphoses, considering them on the example of the concept of freedom. According to A. Fedorovsky: "It is unlikely that the expansion of the degrees of freedom in a paternalistic society, the refusal of the state from responsibility for the fate of its fellow citizens, can generate mass enthusiasm in it" [8].

We turned to the concept of freedom to demonstrate one of the manipulative tricks used by the modern Russian establishment. An example of operating with this concept simultaneously explicates the widely used strategy of axiological variability, in which synonymous concepts are endowed with opposite value signs, depending on the specifics of the current situation and the corresponding goal setting. The appeal to the idea of freedom and responsibility is intensified when there is a search for conceptual grounds for rejecting the state's social obligations to its citizens. On the contrary, the occupation of the living world space by the authorities is accompanied by a value devaluation of the concept we are considering. The latter, in particular, took place within the framework of the adoption of a corpus of laws and legislative acts aimed at strengthening control over the actions of citizens on the Internet. Obviously, Luhmann's law of "self-limitation of the system in its freedom" comes into play, according to which "the system is able to begin to limit its freedoms, exercising it in such a way that can vary from one situation to another" [9]. In general, the recent trend has been the reduction of the private sphere under the slogan of its rationalization, which, however, is facilitated by the possibilities of digital technologies.

Unfortunately, most of the efforts aimed at establishing feedback between the authorities and society are ineffective. Polls show the absence of the expected effect from the work of departmental "online receptions", the "rating" of management structures becomes exclusively formal, and the adopted rating system automatically contributes to the appearance of such a positive image. According to E. Danilova: "The analysis of regulatory documents, the study of the process of formalization and regulation of the procedure for assessing the quality of services provided and the selection of criteria that are approved by law, showed that already in the set parameters it is possible to recognize a strategy that facilitates obtaining positive assessments" [5]. In our opinion, at best, we can talk about optimizing the internal mechanisms of the system's functioning, while maintaining the same quality of services provided. Ultimately, the control system reproduces itself with the preservation of its available qualitative characteristics.

\section{CONCLUSION}

Obviously, other aspects of deformation can also be identified in the communicative process, the subjects of which are power structures and society. However, their analysis is unlikely to be able to significantly affect our ideas about the state of the investigated dialogicity or radically change the received ideas about the relatively low level of explicitness of social management.

The main challenge of the lack of mutual understanding lies in the plane of managerial innovation, when the meaning of innovations is rejected by society due to their false interpretation by the latter, which significantly complicates the implementation of modernization strategies. The situation is complicated by the fact that the recipients of the power message are the bearers of conservative consciousness, which constitute a significant part of the Russian population, which is characterized by an a priori wary attitude towards everything that differs from the standards of the usual picture of the world.

The orientation towards violation of demarcation lines by the power structures, naturally established between the sphere of localization of the former and the life world of Russians, seems extremely destructive. This kind of "invasion" can only lead to formal loyalty, the emergence of a mass social actor, deprived of his own initiative and not participating in the development of the public agenda on an equal footing with the authorities. According to E. Giddens, the "existential contradiction" that inevitably polarizes power and society is reinforced by the so-called "structural contradiction" produced by "a specific characteristic of the state" [10].

Mutual misunderstanding, established between various subjects of social action, is a hindrance to the emergence of broad conventionality, built on mutual respect of the parties with the recognition for each of them both their own autonomy and their own responsibility. It is necessary to think about the formation of a fundamentally new, effective system for the formation of meaning in management activities.

\section{REFERENCES}

[1] V. Petukhov, Civic participation in modern Russia: interaction of political and social practices, Sotsis 12 (2019) 3-15. 
[2] A. Glukhov, The culture of communication management in social media as an element of "digital literacy", Sotsis 5 (2019) 110-119.

[3] I. Tsifanova, Historical events and social structures as factors in the formation of identity in modern society, Stavrolit, 2018.

[4] S. Shevchuk, Discussing the novels of inheritance law: the institution of a social contract, in: Civil law in the 21 st century: current state and development prospects. Materials of the international scientific symposium, October 23-24, 2019, Stavropol, Paragraph, pp. 166-173.

[5] E. Danilova, Institutional innovations in the social sphere: an approach to the study, Sotsis 11 (2019) 1828.

[6] I. Przhilenskaya, The Evolution of the Living World of Russians: The Search for Modernity, SSU Publishing House, 2007.

[7] S. Kirdina-Chandler, M. Kruglova, "Society", "state" and institutional matrices: the experience of interdisciplinary mesoanalysis, Sotsis 10 (2019) 15-27.

[8] A. Fedorovsky, Historical consciousness as a zone of psychological comfort, in: Society and personality: humanization in the context of information and communication culture. Materials of the 6th International Scientific and Practical Conference, Stavropol, ANO VO SKSI Publishing House, 2018, pp. 307-309.

[9] N. Luhmann, Society as a social system, Logos, 2004.

[10] E. Giddens, The organization of society, Academic Project, 2003. 